\title{
RESEARCH BRIEF \\ Rx for Addiction and Medication Safety (RAMS-PEER): Evaluation of an Education and Peer Program on Opioid Misuse
}

\author{
Tianyu Sun, $\mathrm{MS}^{1}$; Ashley L. Buchanan, DrPH, MS ${ }^{1}$; Jeffrey P. Bratberg, PharmD ${ }^{1}$; \\ Emily Patry, $\mathrm{MS}^{1}$; Kelly L. Matson, PharmD ${ }^{1}$
}

\begin{abstract}
Accessible Version: www.cdc.gov/pcd/issues/2020/19_0380.htm
Suggested citation for this article: Sun T, Buchanan AL, Bratberg JP, Patry E, Matson KL. Rx for Addiction and Medication Safety (RAMS-PEER): Evaluation of an Education and Peer Program on Opioid Misuse. Prev Chronic Dis 2020; 17:190380. DOI: https://doi.org/10.5888/pcd17.190380.
\end{abstract}

\section{PEER REVIEWED}

\section{Summary}

What is already known on this topic?

Rhode Island adolescents had among the highest estimated prevalence rates of illicit drug use from 2015 to 2016.

\section{What is added by this report?}

The Rx (prescription) for Addiction and Medication Safety program was developed to deliver opioid misuse education for Rhode Island public high schools to reverse the trend of illicit drug use. Results found student knowledge of opioid misuse and use disorder improved following a pharmacyimplemented intervention. However, spillover benefits were not observed, indicating that consistent program delivery may be needed.

What are the implications for public health practice?

Our study provides evidence of an effective adolescent opioid misuse awareness program and, perhaps, a foundation for a statewide opioid misuse educational program within Rhode Island public schools.

\section{Abstract}

The Rx (prescription) for Addiction and Medication Safety (RAMS) program was developed during the 2017 through 2018 academic year to educate students from 6 selected Rhode Island public high schools about opioid misuse, overdose, and recovery. During 2016, 3 schools participated in the RAMS program and returned for RAMS-PEER in 2017; 3 schools were newly recruited in 2016. Tenth graders returned from schools that participated during RAMS in 2016, and all ninth graders were new. Our study's aim was to evaluate the overall effect and spillover benefit of the
RAMS-PEER intervention from tenth to ninth graders by surveying students both before and after the education program. Survey questions were modified from the 2015 Youth Risk Behavior Survey and the 2015 Ontario Study Survey. Student responses were matched for preintervention and postintervention analysis using a unique identifier. We observed an improvement in knowledge of opioid misuse; however, we found no evidence of a significant spillover benefit.

\section{Introduction}

The United States is facing an unprecedented crisis of drug overdose. More than 70,200 people died from an overdose during 2017 alone. From the 70,200 deaths, 47,600 (68\%) were overdoses from all opioids, and 17,029 (24\%) were overdoses from prescription opioids (1). In Rhode Island, the opioid overdose death rate was 26.9 per 100,000 population and ranked tenth in the United States in 2017. RI adolescents were especially at high risk of substance misuse. Based on the 2015-2016 National Survey on Drug Use and Health, RI had one of the highest estimated percentages of adolescents (aged 12 to 17 y) who used illicit drugs, $12.5 \%(95 \%$ confidence interval [CI], 10.18\%-15.19\%), compared with the national average of $8.3 \%(95 \% \mathrm{CI}, 7.98 \%-8.71 \%)(2)$.

To prevent opioid misuse and overdose among youth, we implemented the Rx for Addiction and Medication Safety (RAMS) program. Developed by the University of Rhode Island (URI) College of Pharmacy, RAMS was an opioid misuse prevention education program delivered by trained pharmacy students for freshmen students at 8 public high schools in Rhode Island during the 2016 through 2017 academic year. Of students surveyed, 33 (7\%) significantly improved their identification of opioid misuse, $19 \%$ improved knowledge of opioid withdrawal symptoms, $14 \%$ improved knowledge of the need for treatment referral, and $28 \%$ improved knowledge of naloxone administration (3). The PEER program was developed as a 1-hour, online, supplemental curriculum for RAMS. We implemented the RAMS-PEER program during 
the subsequent 2017 through 2018 academic year to boost learning effects and evaluate potential spillover benefit of peer education. Three of 8 schools from the previous academic year returned to the program, and 3 new public high schools began participation. We delivered the booster course only to tenth-grade students from the returning schools who had participated in the RAMS program during the previous year. The full 3-hour RAMS curriculum was then delivered to ninth graders in all 6 schools.

\section{Purpose and Objectives}

Our study aimed to evaluate the overall effect and possible spillover benefit of the RAMS-PEER intervention among high school students, specifically, to determine if tenth graders participating in the prior year shared their knowledge with incoming ninth graders (4-6). Leveraging spillover mechanisms to sustainably scale up and deliver the RAMS intervention is necessary, given the often resource-constrained setting of public-school systems. Recent evidence points to stronger influences of peer-to-peer education for risk reduction, as compared with provider-to-peer, and we anticipated this resonance might be stronger among adolescent peers $(5,7)$. We conclude with a discussion of next steps to evaluate spillover of the RAMS-PEER intervention.

\section{Intervention Approach}

RAMS is a 3-hour, on-site, school-based curriculum, providing 3 to 4 interactive educational sessions. Sessions include medication safety, signs, symptoms, and risk factors for opioid misuse and withdrawal; opioid overdose identification and response; and local treatment and recovery resources. Implementation of RAMS has been described previously (3). The RAMS-PEER program is a booster curriculum for RAMS and designed as an online supplement. Seven, 5-minute videos were created for RAMS-PEER to highlight RAMS education, and the curriculum includes facilitator guides for instructors' in-class discussions. All RAMS-PEER materials were available on the RAMS-PEER website (www.ramspeer.com) during the program's implementation. Returning tenth graders who had received the RAMS curriculum in the first year were instructed to view videos either in school or in their spare time. A discussion led by high-school faculty was mandatory after each booster video. Once completed, URI pharmacy students delivered the primary RAMS program to ninth graders at both new and returning schools.

\section{Evaluation Methods}

We conducted a pre-post comparison study to measure an initial RAMS-PEER intervention on student knowledge, perceptions, risk, and protective behaviors related to opioid misuse. Our study population included students entering the ninth and tenth grades during the 2017 through 2018 academic year. Students voluntarily participated in 2 confidential surveys answering questions by using SurveyMonkey (SVMK, Inc). Before program delivery (preintervention), ninth graders completed a 20 -minute survey that included risk and protective factors for substance misuse; past 30 days nonmedical use of opioids, alcohol use, and use of other substances; students' perception of risk or harm from prescription drugs and prescription drug overdose; awareness of resources and treatment of substance misuse; proper disposal and storage of prescription medications; and how to obtain and administer naloxone. These items were modified from the 2015 Youth Risk Behavior Survey from the Centers for Disease Control and Prevention and the 2015 Ontario Study Survey from the Canadian Centre for Addiction and Mental Health and identical to surveys administered in the RAMS first-year program $(3,8,9)$. The survey also collected student demographic information, such as age, race/ethnicity, and sex, as well as home environment, social media use, self-reported mental health, academic assessment, and substance use. The same survey was administrated again 1 to 2 months after the RAMSPEER curriculum was completed among the ninth and tenth graders (postintervention). In this analysis, the intervention was a booster for tenth graders from returning schools and a full curriculum for ninth graders from all 6 schools. All postsurveys were administered after all students received the full intervention. Each student response was matched for preintervention and postintervention analysis using a unique identifier.

Descriptive statistics, including means and proportions, were used to report participant demographics and other characteristics. We used the $\chi^{2}$ test to conduct cross-sectional and paired comparisons between outcomes at the 6 schools at preintervention and postintervention. Because the matched sample had missing values $(\mathrm{n}=$ $129,40 \%$ ), a multiple imputation approach was used with discriminant function for categorical variables to impute missing values. We used the fully conditional specification method to impute the missing data. Multiple imputation was performed on combined preintervention and postintervention data to generate 30 data sets with complete information, assuming a multivariate normal distribution and that missing data depended only on observed covariates $(10,11)$. CIs for imputation results were based on standard errors using Rubin's estimator of variance (12). To assess if ninth grade students in returning schools had an associated improvement in knowledge due to the educational program (RAMS) and the booster (PEER), as compared with ninth grade students in new schools who received only RAMS, we fit a logistic model with binary versions of each outcome (responses to knowledge questions were identified as either correct or incorrect; 5-level confidence questions were dichotomized into 2 groups (eg, none of your closest friends use pain relief pills versus at least some). In the

The opinions expressed by authors contributing to this journal do not necessarily reflect the opinions of the U.S. Department of Health and Human Services, the Public Health Service, the Centers for Disease Control and Prevention, or the authors' affiliated institutions. 
models for matched precomparisons and postcomparisons, each student served as their own control; therefore, time-invariant confounding was subtracted by individual level differencing, and secular trends were less of a concern, short of a follow-up period. We also included the confounders of age, sex, race, grade, access to pain relief, and mental health (significance set at $P<.20$ ) in the logistic model evaluating the association of school type on outcomes. Statistical analysis was completed using SAS Version 9.4 (SAS Institute, Inc), and all tests were 2 -sided at $P<.05$ significance.

To evaluate the possible spillover and peer education benefit from tenth to ninth graders in returning schools, we calculated the adjusted odds ratios (aORs) of correct responses or improvement in knowledge among ninth graders in returning schools versus ninth graders in new schools. Improvement in knowledge was defined as having correct answers in both the presurvey and the postsurvey, or having incorrect answers in presurvey and correct answers in the postsurvey.

\section{Results}

Of ninth grade students in 2017 through 2018, 1,030 participated in the preintervention survey, and 439 participated in the postintervention survey. We matched 321 students with both preintervention and postintervention surveys for the year. Most ninth graders from the 6 high schools were aged 14 or 15 years $(n=1,013$, $98.3 \%), 823$ were white $(79.9 \%)$, and $908(88.2 \%)$ earned nearly all A and B grades. Of the 1,030 students, 715 (69.4\%) reported good mental health status, with no feelings of worthlessness $(\mathrm{n}=$ $594,57.7 \%)$ or hopelessness $(n=622,60.4 \%)$. Additionally, 707 students found it difficult or did not know how to obtain pain relief medication $(68.6 \%)$ or medication to treat attention deficit hyperactivity disorder without prescription $(n=759,73.7 \%)$ (Table 1).

After the RAMS-PEER program, during the 2017 through 2018 academic year, ninth grade student knowledge of opioid misuse improved. The percentage of correct answers increased significantly from preintervention to postintervention for questions on knowledge of opioid misuse (from $76.2 \%$ correct to $84.4 \%$ correct), and perceptions of people who use drugs (from $27.4 \%$ correct to $33.9 \%$ correct) (Table 2 ).

Improvement was observed among matched ninth graders $(\mathrm{n}=$ 321) regarding their knowledge that accepting a prescription medication from a friend was drug misuse. For Question 93, $P=.01$ (Table 2). After receiving the intervention, among the matched students, we observed an $8 \%$ increase in knowledge of identifying addiction as a chronic brain disorder (aOR, 1.08; 95\% CI, $0.64-1.83$ ), a $26 \%$ increase in understanding of reasons people use drugs (aOR, 1.26; 95\% CI, 0.79-1.98), and a 78\% increase in knowledge that nonmedical use is using a prescription medication without a prescription (aOR, 1.78; 95\% CI, 0.87-3.6) (Table 2). Knowledge improvement, however, was not significantly higher among ninth graders in the returning schools versus ninth graders in the new schools.

\section{Implications for Public Health}

In our assessment of an opioid misuse education program among ninth- and tenth-grade students in Rhode Island, we found that ninth-grade students had improved knowledge of opioid misuse and improved perceptions of people who use drugs after the education program during the 2017 through 2018 academic year, demonstrating effectiveness of the program. We also found a positive, although nonsignificant, spillover effect among ninth graders from the 3 returning schools. Although a more robust assessment of the spillover mechanism is needed, these findings indicate that an educational awareness and prevention program needs consistent delivery to provide beneficial outcomes.

Our study has several limitations. Although each school administration approved survey implementation, the Rhode Island Department of Education halted it for several months before revoking the approval midstudy. Approval was again obtained after the department's expanded review of the identical survey; however, critical time lost during the study negatively affected data collection and limited evaluation of spillover effects. We received 1,030 preintervention survey respondents from ninth graders; however, only 415 students completed the postsurvey, and we were only able to match 321 pre- and postrespondents. The preintervention survey had approximately $30 \%$ missing answers and the postintervention survey had approximately $20 \%$ missing. A low response rate to the postsurvey and missing outcomes limited our ability to detect improvements in knowledge. Another limitation was our use of a fully conditional specification, a semiparametric method that is flexibly suitable for this study. One known theoretical limitation of this study is its high sensitivity to imputing values, and this might have affected our results (13). To avoid this drawback we imputed variables following the order that they appeared in the survey, which was appropriate and matched the monotone pattern of missing data. Additionally, selection bias might have been introduced by student self-reports of earning A or B grades. Students who received good grades might have been more likely to respond to the survey than students who received lower grades.

Future studies could use a randomized design, which might provide a more accurate evaluation of spillover effects of the RAMS-PEER intervention and offer additional insights into the

The opinions expressed by authors contributing to this journal do not necessarily reflect the opinions of the U.S. Department of Health and Human Services, the Public Health Service, the Centers for Disease Control and Prevention, or the authors' affiliated institutions. 
intervention coverage levels needed to change and sustain norms around opioid misuse among adolescents.

\section{Acknowledgments}

This work was supported by CVS Health. CVS Health did not have a role in study design, collection or analysis of data, or in writing this article. The findings and conclusions in this report are those of the authors and do not necessarily represent the official position of the Centers for Disease Control and Prevention. No borrowed material or copyrighted surveys, instruments, or tools were used for this article without permission.

\section{Author Information}

Corresponding Author: Tianyu Sun, MS, Social Science Research Center, 130 Flagg Road, Room 6, Kingston, RI 02881. Telephone: 401-874-4739. Email: tysun@uri.edu.

Author Affiliations: ${ }^{1}$ University of Rhode Island, Department of Pharmacy Practice, Kingston, Rhode Island.

\section{References}

1. Scholl L, Seth P, Kariisa M, Wilson N, Baldwin G. Drug and opioid-involved overdose deaths — United States, 2013-2017. MMWR Morb Mortal Wkly Rep 2018;67(5152):1419-27.

2. Substance Abuse and Mental Health Services Administration. 2015-2016 National Survey on Drug Use and Health: modelbased prevalence estimates (50 states and the District of Columbia)

3. Patry E, Bratberg JP, Buchanan A, Paiva AL, Balestrieri S, Matson KL. Rx for addiction and medication safety: an evaluation of teen education for opioid misuse prevention. Res Social Adm Pharm 2019;15(8):917-24.

4. Hudgens MG, Halloran ME. Toward causal inference with interference. J Am Stat Assoc 2008;103(482):832-42.

5. Buchanan AL, Vermund SH, Friedman SR, Spiegelman D. Assessing individual and disseminated effects in networkrandomized studies. Am J Epidemiol 2018;187(11):2449-59.

6. Benjamin-Chung J, Arnold BF, Berger D, Luby SP, Miguel E, Colford JM Jr, et al. Spillover effects in epidemiology: parameters, study designs and methodological considerations. Int J Epidemiol 2018;47(1):332-47.

7. Ghosh D, Krishnan A, Gibson B, Brown S-E, Latkin CA, Altice FL. Social network strategies to address HIV prevention and treatment continuum of care among at-risk and HIVinfected substance users: a systematic scoping review. AIDS Behav 2017;21(4):1183-207.
8. Kann L, McManus T, Harris WA, Shanklin SL, Flint KH, Hawkins J, et al. Youth Risk Behavior Surveillance - United States, 2015. MMWR Surveill Summ 2016;65(6):1-174.

9. Boak A, Hamilton HA, Adlaf EM, Henderson JL, Mann RE. The mental health and well-being of Ontario students, 1991-2015: detailed OSDUHS findings. Centre for Addiction and Mental Health. Toronto, ON; document series No. 43, 2016.

10. Harel O, Mitchell EM, Perkins NJ, Cole SR, Tchetgen Tchetgen EJ, Sun B, et al. Multiple imputation for incomplete data in epidemiologic studies. Am J Epidemiol 2018; 187(3):576-84.

11. Perkins NJ, Cole SR, Harel O, Tchetgen Tchetgen EJ, Sun B, Mitchell EM, et al. Principled approaches to missing data in epidemiologic studies. Am J Epidemiol 2018;187(3):568-75.

12. Rubin DB. Comment: a noniterative sampling/importance resampling alternative to the data augmentation algorithm for creating a few imputations when fractions of missing information are modest: the SIR algorithm. J Am Stat Assoc 1987;82(398):543-6.

13. van Buuren S. Multiple imputation of discrete and continuous data by fully conditional specification. Stat Methods Med Res 2007;16(3):219-42.

The opinions expressed by authors contributing to this journal do not necessarily reflect the opinions of the U.S. Department of Health and Human Services, the Public Health Service, the Centers for Disease Control and Prevention, or the authors' affiliated institutions. 


\section{Tables}

Table 1. RAMS-PEER Intervention Surveys and Matched Respondent Demographic Characteristics Among Ninth Grade Students, Rhode Island, 2017

\begin{tabular}{|c|c|c|}
\hline Characteristic & RAMS-PEER 2017 Presurvey, $N=1030, n(\%)^{a}$ & RAMS-PEER 2017 Matched Presurvey and Postsurvey, $\mathrm{N}=321, \mathrm{n}(\%)^{\mathrm{a}}$ \\
\hline \multicolumn{3}{|l|}{ Sex } \\
\hline Female & 493 (47.9) & $190(59.2)$ \\
\hline Male & $518(50.3)$ & $128(39.9)$ \\
\hline Other & $19(1.8)$ & $3(0.9)$ \\
\hline \multicolumn{3}{|l|}{ Age, y } \\
\hline 14 & $551(53.5)$ & $127(39.6)$ \\
\hline 15 & $462(44.9)$ & $188(58.6)$ \\
\hline 16 & $11(1.1)$ & $5(1.6)$ \\
\hline 17 & $6(0.6)$ & $1(0.3)$ \\
\hline \multicolumn{3}{|l|}{ Race } \\
\hline White & $823(79.9)$ & $271(84.4)$ \\
\hline Other & $207(20.1)$ & $50(15.6)$ \\
\hline \multicolumn{3}{|l|}{ Grades } \\
\hline B or better & $908(88.2)$ & $299(93.2)$ \\
\hline Less than B & $122(11.8)$ & $22(6.9)$ \\
\hline \multicolumn{3}{|c|}{ Daily social media use, $h$} \\
\hline$<2$ & 349 (33.9) & $109(34.0)$ \\
\hline $2-4$ & $481(46.7)$ & $148(46.1)$ \\
\hline$>5$ & $199(19.3)$ & $64(19.9)$ \\
\hline Missing & $1(0.1)$ & 0 \\
\hline \multicolumn{3}{|c|}{ How easy or difficult would it be for you to get pain relief pills without going to a doctor? } \\
\hline Easy & $269(26.1)$ & $88(27.4)$ \\
\hline Difficult & $400(38.8)$ & $142(44.2)$ \\
\hline I don't know & $307(29.8)$ & $78(24.3)$ \\
\hline Missing & $54(5.2)$ & $13(4.0)$ \\
\hline \multicolumn{3}{|c|}{ How easy or difficult would it be for you to ADHD medications without going to a doctor? } \\
\hline Easy & 205 (19.9) & $74(23.1)$ \\
\hline Difficult & $419(40.7)$ & $146(45.5)$ \\
\hline I don't know & $340(33.0)$ & $86(26.8)$ \\
\hline Missing & $66(6.4)$ & $15(4.7)$ \\
\hline \multicolumn{3}{|c|}{ Self-reported emotional health } \\
\hline Good & $715(69.4)$ & $219(68.2)$ \\
\hline Poor & $63(6.1)$ & $19(5.9)$ \\
\hline Missing & $252(24.5)$ & $83(25.9)$ \\
\hline
\end{tabular}

Abbreviations: ADHD, attention deficit hyperactivity disorder; RAMS, Rx for Addiction and Medication Safety.

a Values of polytomous variables might not sum to $100 \%$ due to rounding. 
(continued)

Table 1. RAMS-PEER Intervention Surveys and Matched Respondent Demographic Characteristics Among Ninth Grade Students, Rhode Island, 2017

\begin{tabular}{|c|c|c|}
\hline Characteristic & RAMS-PEER 2017 Presurvey, $\mathrm{N}=1030, \mathrm{n}(\%)^{\mathrm{a}}$ & RAMS-PEER 2017 Matched Presurvey and Postsurvey, $N=321, n(\%)^{a}$ \\
\hline \multicolumn{3}{|c|}{ Self-reported hopeless feeling } \\
\hline Little or no & $594(57.7)$ & $169(52.7)$ \\
\hline Some time or more & $178(17.3)$ & $67(20.9)$ \\
\hline Missing & $258(25.1)$ & $85(26.5)$ \\
\hline \multicolumn{3}{|c|}{ Self-reported worthless feeling } \\
\hline Little or no & $622(60.4)$ & $186(57.9)$ \\
\hline Some time or more & $150(14.6)$ & $50(15.6)$ \\
\hline Missing & $258(25.1)$ & $85(26.5)$ \\
\hline
\end{tabular}

Abbreviations: ADHD, attention deficit hyperactivity disorder; RAMS, Rx for Addiction and Medication Safety.

${ }^{a}$ Values of polytomous variables might not sum to $100 \%$ due to rounding. 
Table 2. Improved Knowledge Comparison Among Ninth Grade Students From Returning Schools Versus New Schools, Rhode Island, Academic Year 2017-2018

\begin{tabular}{|c|c|c|c|c|c|c|c|}
\hline $\begin{array}{l}\text { Questions (Q) and } \\
\text { Dichotomized Answers }\end{array}$ & $\begin{array}{l}2017 \text { Presurvey } \\
N=1,030, n(\%)\end{array}$ & $\begin{array}{l}2017 \text { Postsurvey } \\
N=415, n(\%)\end{array}$ & $P$ Value $^{\mathrm{a}}$ & $\begin{array}{l}\text { Matched } 2017 \\
\text { Presurvey } \\
\mathrm{N}=321, \mathrm{n}(\%)\end{array}$ & $\begin{array}{l}\text { Matched } 2017 \\
\text { Postsurvey } \\
\mathrm{N}=321, \mathrm{n}(\%)\end{array}$ & $P$ Value & $\begin{array}{l}\text { Adjusted Odds Ratios } \\
\text { (95\% Confidence } \\
\text { Interval) }\end{array}$ \\
\hline \multicolumn{8}{|c|}{ Q93 Addiction is a chronic brain disease or disorder. ${ }^{\text {b }}$} \\
\hline Correct & $591(79.3)$ & $284(83.5)$ & .10 & $191(82.0)$ & $232(86.6)$ & .15 & $1.08(0.63-1.83)$ \\
\hline \multicolumn{8}{|c|}{ Q93 Drug misuse is accepting prescription medication from a friend. ${ }^{\mathrm{b}}$} \\
\hline Correct & $568(76.2)$ & $287(84.4)$ & .01 & $181(77.7)$ & $230(85.8)$ & .01 & $0.72(0.44-1.18)$ \\
\hline \multicolumn{8}{|c|}{ Q93 Drug misuse is use of a prescription medication is exceeding the recommended dose. ${ }^{b}$} \\
\hline Correct & $653(87.7)$ & $305(89.7)$ & .33 & $208(89.3)$ & $245(91.4)$ & .41 & $0.85(0.48-1.51)$ \\
\hline \multicolumn{8}{|c|}{ Q93 Nonmedical use is using a prescription medication without a prescription. ${ }^{\text {b }}$} \\
\hline Correct & $634(85.1)$ & 299 (87.9) & .21 & $209(89.7)$ & $240(89.6)$ & .95 & $1.77(0.86-3.63)$ \\
\hline \multicolumn{8}{|c|}{ Q100 Drug users are responsible for their addiction. ${ }^{\mathrm{C}}$} \\
\hline Correct & $202(27.4)$ & $114(33.9)$ & .03 & $67(29.0)$ & $91(34.2)$ & .21 & $0.93(0.60-1.44)$ \\
\hline \multicolumn{8}{|c|}{ Q100 Drug users can stop using drugs whenever they want to. ${ }^{c}$} \\
\hline Correct & $557(75.5)$ & $272(81.0)$ & .05 & $182(78.8)$ & $22(83.1)$ & .22 & $1.13(0.70-1.82)$ \\
\hline \multicolumn{8}{|c|}{ Q100 People use drugs to avoid dealing with their own inadequacies. ${ }^{c}$} \\
\hline Correct & $128(17.3)$ & $80(23.8)$ & .01 & $40(17.3)$ & $53(19.9)$ & .45 & $1.26(0.79-1.98)$ \\
\hline \multicolumn{8}{|c|}{ Q100 Drug users have weak characters ${ }^{c}$} \\
\hline Correct & $442(59.9)$ & $213(63.4)$ & .28 & $147(63.6)$ & $17(63.9)$ & .95 & $0.97(0.65-1.43)$ \\
\hline \multicolumn{8}{|c|}{ Q76 Feel so depressed (sad) that nothing could cheer you up? ${ }^{d}$} \\
\hline None & $489(63.3)$ & $204(58.1)$ & .09 & $138(58.5)$ & $16(58.8)$ & .93 & $1.16(0.75-1.81)$ \\
\hline $\begin{array}{l}\text { A little, sometime, most time, } \\
\text { or all the time }\end{array}$ & $283(36.7)$ & $147(41.9)$ & NA & $98(41.5)$ & $11(41.2)$ & NA & NA \\
\hline \multicolumn{8}{|c|}{ Q78 In the last 4 weeks, did you feel that you were under any stress, strain, or pressure? ${ }^{d}$} \\
\hline Not at all & $101(13.1)$ & $47(13.4)$ & .89 & $20(8.5)$ & $34(12.3)$ & .16 & $1.96(0.83-4.61)$ \\
\hline $\begin{array}{l}\text { A little, some, a lot, or more } \\
\text { than I could take }\end{array}$ & $671(86.9)$ & $304(86.6)$ & NA & $216(91.5)$ & $24(87.7)$ & NA & NA \\
\hline \multicolumn{8}{|c|}{ Q83 How many of your CLOSEST friends use pain relief pills such as Percocet, Tylenol \#3, Vicodin, Oxycodone? ${ }^{\mathrm{e}}$} \\
\hline None & $540(70.8)$ & $242(69.3)$ & .628 & $160(68.1)$ & $19(69.2)$ & .78 & $0.92(0.64-1.39)$ \\
\hline Some, most, all, or don't know & $223(29.2)$ & $107(30.7)$ & NA & 75 (31.9) & $85(30.8)$ & NA & NA \\
\hline \multicolumn{8}{|c|}{ Q97 My parent(s) showed me affection. ${ }^{f}$} \\
\hline Always or frequently & $640(86.7)$ & $284(84.5)$ & .34 & $201(87.0)$ & $22(85.7)$ & .67 & $1.38(0.76-2.52)$ \\
\hline Sometimes or rarely & $98(13.3)$ & $52(15.5)$ & NA & $30(13.0)$ & 38 (14.3) & NA & NA \\
\hline
\end{tabular}

${ }^{a} P$ value was calculated by using $x^{2}$ test.

${ }^{\mathrm{b}} 285$ Missing values in 2017 presurvey, 75 in 2017 postsurvey, 88 in matched presurvey, and 53 in matched postsurvey.

c 292 Missing values in 2017 presurvey, 79 in 2017 postsurvey, 90 in matched presurvey, and 55 in matched postsurvey.

d 258 Missing values in 2017 presurvey, 64 in 2017 postsurvey, 85 in matched presurvey, and 44 in matched postsurvey.

e 267 Missing values in 2017 presurvey, 66 in 2017 postsurvey, 86 in matched presurvey, and 45 in matched postsurvey.

f 292 Missing values in 2017 presurvey, 79 in 2017 postsurvey, 90 in matched presurvey, and 55 in matched postsurvey.

The opinions expressed by authors contributing to this journal do not necessarily reflect the opinions of the U.S. Department of Health and Human Services, the Public Health Service, the Centers for Disease Control and Prevention, or the authors' affiliated institutions. 